\title{
Epidemiological characteristics of human prion diseases
}

\author{
Cao Chen ${ }^{1,2}$ and Xiao-Ping Dong ${ }^{1,2,3^{*}}$
}

\begin{abstract}
Human prion diseases are a group of transmissible, progressive, and invariably fatal neurodegenerative disorders, which include Kuru, Creutzfeldt-Jakob disease (CJD), Gerstmann-Sträussler-Scheinker syndrome, and fatal familial insomnia. Human prion diseases affect approximately 1-2 persons per million worldwide annually, occurring in sporadic, inherited, and acquired forms. These diseases have attracted both scientific and public attention not only because of their mysterious pathogen, but also due to their considerable threat to public health since the emergence of the variant CJD.

There are still no specific therapeutic and prophylactic interventions available for prion diseases, thus active surveillance of human prion diseases is critical for disease control and prevention. Since 1993, CJD surveillance systems have been established in many countries and regions, and several long-term multinational cooperative projects have been conducted.

In this paper, the epidemiological characteristics of various human prion diseases and the active surveillance systems pertaining to them in different countries and regions are summarized and reviewed.
\end{abstract}

Keywords: Prion disease, Epidemiology, Creutzfeldt-Jakob disease, Surveillance

\section{Multilingual abstract}

Please see Additional file 1 for translations of the abstract into the six official working languages of the United Nations.

\section{Background}

Human prion diseases, also named transmissible spongiform encephalopathies (TSEs), are fatal neurodegenerative disorders, which include Kuru, Creutzfeldt-Jakob disease (CJD), Gerstmann-Sträussler-Scheinker syndrome (GSS), and fatal familial insomnia (FFI). These various subtypes have different characteristics based on the onset times/durations of the disease, genetic/family histories of the patients, clinical manifestations, neuropathology, and scrapie-like prion protein $\left(\mathrm{PrP}^{\mathrm{Sc}}\right)$ molecular features $[1,2]$. It is widely accepted that TSEs result from the conformational conversion of a normal cellular prion protein $\left(\mathrm{PrP}^{\mathrm{C}}\right)$ into an

\footnotetext{
* Correspondence: dongxp238@sina.com

${ }^{1}$ State Key Laboratory for Infectious Disease Prevention and Control, National Institute for Viral Disease Control and Prevention, Chinese Center for Disease Control and Prevention, Changbai Rd 155, Beijing 102206, China

${ }^{2}$ Collaborative Innovation Center for Diagnosis and Treatment of Infectious

Diseases, Zhejiang University, Hangzhou 310003, China

Full list of author information is available at the end of the article
}

abnormal misfolded pathological form $\left(\mathrm{PrP}^{\mathrm{Sc}}\right)$. An accumulation of $\mathrm{PrP}^{\mathrm{Sc}}$ leads to the onset of TSEs, which attack the central nervous system, resulting in progressive neuronal degeneration and neuronal vacuolation [3].

Currently, Kuru is virtually extinct due to a ban on ritualistic cannibalism in the area of Papua New Guinea where it was endemic. Most of the human prion diseases are CJD, which consist of three main catalogues: sporadic, genetic, and acquired [1]. Approximately 85-90 \% of CJD cases occur sporadically and affect $1-1.5$ people per million annually [4]. Familial/genetic CJD (fCJD/ gCJD) account for about $10 \%$ of CJD cases worldwide [5]. Acquired prion diseases include variant CJD (vCJD) and iatrogenic CJD (iCJD), and are observed in 2-5\% of CJD cases. Depending on the origin of the causative agent, human prion diseases can be divided into two groups: caused by prions originating internally, such as in the case of fCJD/gCJD, GSS, and FFI; or infected by external prions, such as in the case of Kuru, iCJD, and vCJD [6].

The pathogenesis of sporadic CJD (sCJD) is little known. Many case-control studies on the risk factors for SCJD have been conducted, with varying results, but 
no consistent data are available [7-12]. However, the opportunity of external prion infection is still not easy to be excluded definitely during long life-span [13].

As there are no specific therapeutic and prophylactic interventions available for prion diseases, active surveillance is critical for the control and prevention of human prion diseases, especially those diseases caused by animal-derived prion agents. Since 1993, many national CJD surveillance systems have been established and several multinational cooperative organizations have also been set up for CJD surveillance and research [14-18]. In the present review, the epidemiological characteristics of various subtypes of human prion diseases and the active surveillance systems pertaining to them are summarized and discussed.

\section{Epidemiological characteristics of human prion diseases \\ SCJD}

CJD was first described in the early 1920s [19, 20]. The predominant subtype of human prion diseases, SCJD, occurs equally in both sexes with a peak age of onset between 60 and 69 years [21-23]. sCJD occurs all year round, with no seasonal specificity. Typical clinical symptoms include progressive dementia, accompanied by visual and cerebellum function abnormalities, myoclonia, pyramidal and extrapyramidal dysfunction, or akinetic mutism [2, 21]. The duration of SCJD cases is relatively short. The median survival time of Chinese sCJD cases is 7.1 months (range: $1.0-23.3$ ) and $78.5 \%$ of patients die within one year of onset [24]. These data are comparable with that of Western countries but differ to data from Japan. A study conducted by the European CJD Surveillance Network (EuroCJD) involving 2,451 sCJD patients, who died between 31 December 1992 and 31 December 2002, revealed that the median survival time was five months (range: $1-81$ ) and that $85.8 \%$ of patients died within one year of onset [25]. In Argentina, the median disease duration of sCJD (calculated using 150 definite and probable cases from available data) is 4.6 months (range: 1-70) [17]. On the contrary, a survey by the Japanese CJD surveillance program showed significantly longer disease durations in Japanese patients with prion diseases (most of them with the sCJD subtype), in which the mean disease duration of 855 patients was 17.4 months and only $46.0 \%$ died within one year of onset. This is likely attributed to the country's healthcare system, which provides intensive life-sustaining treatment for patients [26]. There is no accessible data for SCJD cases in South Asia or Africa.

An international study on the epidemiologic characteristics of sCJD involving 3,720 sCJD cases from nine European countries, as well as from Australia and Canada, revealed that the overall annual mortality rate from sCJD is 1.39 per million [27]. In Japan, the age- adjusted mortality rates have increased from 1979 to 2004, with the annual mortality rate of 1.48 per million in 2004 [28]. The Chinese CJD surveillance network reported that the annual CJD morbidity rate in Beijing is 0.91 per million [29]. The recognition of CJD clinically and the undertaking of national CJD surveillance influences a country's mortality rate. According to the latest data from the CJD International Surveillance Network (formerly the EuroCJD), the countries with the highest mean mortality rates per million from SCJD are France and Switzerland (1.51 and 1.72, respectively). The mean mortality rates per million from sCJD from 1993 to 2013 of some countries are shown in Fig. 1a; 16 out of 28 countries have a mean mortality rate per million greater than 1.0. Averaging the annual data from all countries in the CJD International Surveillance Network from 1993 to 2013 results in the mortality rates per million increased (see Fig. 1b). In the United States (US), the annual mortality rate is approximately one per million based on data from 1979 to 2006 [30]. However, it is important to note that most CJD cases from these data were European Americans (94.6\%) and that the age-adjusted incidence of whites is 2.7 times higher than that of African Americans (1.04 and 0.40, respectively) [30], and is also higher than that of Native Americans and Alaska Natives (0.47) [31]. Although reasons for such disparities are unclear, it is possible that genetic differences and/or under diagnosis among non-white patients are two associated factors.

\section{Genetic human prion diseases}

The human gene encoding for the prion protein $(\operatorname{PrP})$, $P R N P$, is located on chromosome 20p12 in humans. To date, more than 40 mutations in the PRNP gene have been directly linked to familial prion diseases, including fCJD/ gCJD, GSS, and FFI [32]. These mutations include point mutations in the PRNP sequence, and octapeptide repeat insertions or deletions in PrP's N-terminus. Several epidemiological surveys report that some patients with genetic prion diseases lack definite family history $[33,34]$.

The distribution and frequency of mutations in the PRNP gene vary significantly among geographical areas and human races. In gCJD/fCJD, the three most common PRNP mutations in European Caucasians, North Americans, and Australians are E200K, V210I, and D178N/ $129 \mathrm{~V}$ [34]. Interestingly, E200K is the only mutation in the PRNP gene reported in the Slovak population, whereas only one E200K gCJD case was identified in the population of Switzerland between 1996 and 2002, and no E200K gCJD has been reported after this. The proportionate incidence of the V210I mutation in the Italian population is obviously higher than that in other ten countries (50 out of 69 V210I gCJD cases are observed in Italy), according to data from the EuroCJD 1993-2002 [35]. In Japan, the most frequently observed mutation in the PRNP gene is 


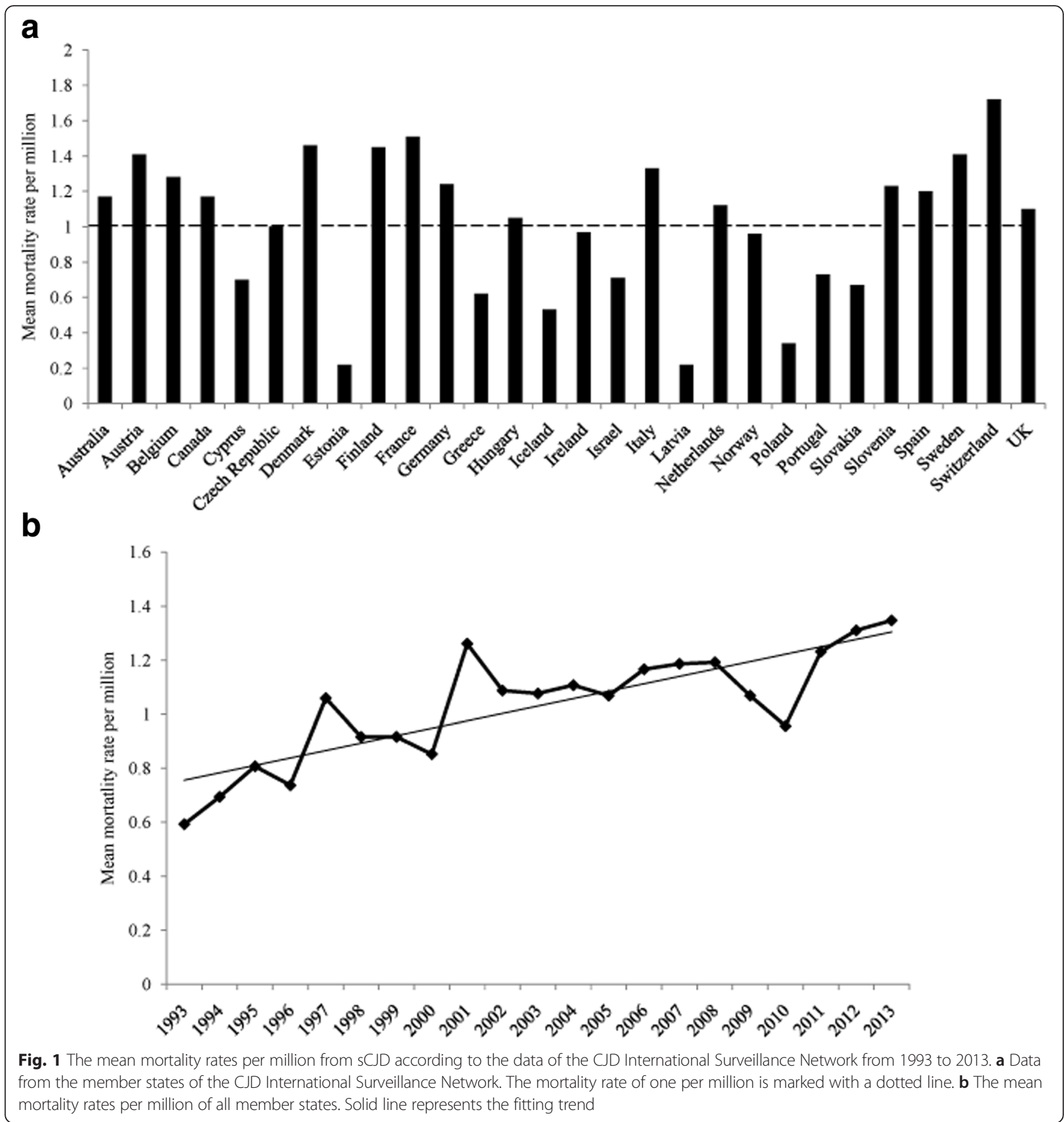

V180I, followed by E200K and M232R [16], while the mutations T188K and E200K are most frequent in China [36]. Five mutations in codon 180, three in codon 200, two in codon 203, and two in codon 232 have been identified in the Republic of Korea [37-42]. The frequency of gCJD cases in the Republic of Korea is similar to that in Japan, but differs from that in China (see Table 1) [43]. In addition, the V210I mutation is prevalent in European countries but is rare in East Asian populations. M232R, which is one of the most frequently described gCJD- associated mutations in the Japanese, is rarely identified among Europeans.

The distribution and frequency of mutations in the PRNP gene causing GSS are also clearly distinct between Caucasians and East Asians. Although the most common mutation causing GSS in Caucasian and East Asian patients is $\mathrm{P} 102 \mathrm{~L}$, the mutation P105L is only observed in East Asian populations, especially in the Japanese, while the mutation $\mathrm{A} 117 \mathrm{~V}$ is exclusively reported in Caucasians. 
Table 1 The distribution of genetic prion diseases in European and East Asians countries

\begin{tabular}{|c|c|c|c|c|c|c|c|}
\hline \multirow[t]{2}{*}{ Diseases } & \multirow[t]{2}{*}{ Mutations } & \multirow{2}{*}{$\begin{array}{l}\text { Europeans [27] } \\
\text { Total }(n=420)\end{array}$} & \multicolumn{4}{|c|}{ East Asians $[10,29,31-35]$} & \multirow[t]{2}{*}{$P$-value ${ }^{a}$} \\
\hline & & & China $(n=62)$ & Japan $(n=216)$ & Korea $(n=15)$ & Total $(n=293)$ & \\
\hline \multirow[t]{13}{*}{ gCJD } & Insertion & 39 & 2 & 3 & 0 & 5 & $P<0.001$ \\
\hline & N171S-129 V & 1 & 0 & 0 & 0 & 0 & n.s. \\
\hline & D178N-129 V & 16 & 0 & 1 & 0 & 1 & $P<0.01$ \\
\hline & V180l-129 M & 1 & 1 & 89 & 5 & 95 & $P<0.001$ \\
\hline & T188A-129 M & 3 & 0 & 0 & 0 & 0 & n.s. \\
\hline & T188K-129 M & 0 & 16 & 0 & 0 & 16 & $P<0.001$ \\
\hline & E196K-129 MN & 5 & 1 & 0 & 0 & 1 & n.s. \\
\hline & E200K-129 MN & 175 & 9 & 37 & 3 & 49 & $P<0.001$ \\
\hline & V2031-129 M & 5 & 1 & 2 & 2 & 5 & n.s. \\
\hline & $\mathrm{R} 208 \mathrm{H}-129 \mathrm{M}$ & 2 & 2 & 1 & 0 & 3 & n.s. \\
\hline & V210l-129 M & 69 & 0 & 0 & 0 & 0 & $P<0.001$ \\
\hline & E211Q-129 M & 4 & 0 & 0 & 0 & 0 & n.s. \\
\hline & M232R-129 M & 0 & 0 & 33 & 2 & 35 & $P<0.001$ \\
\hline \multirow[t]{3}{*}{ GSS } & P102L-129 M & 24 & 3 & 39 & 2 & 44 & $P<0.001$ \\
\hline & P105L-129 M & 0 & 0 & 5 & 0 & 5 & $P<0.05$ \\
\hline & A117V-129 V & 12 & 0 & 0 & 0 & 0 & $P<0.01$ \\
\hline $\mathrm{FFI}$ & D178N-129 M & 64 & 27 & 3 & 1 & 31 & n.s. \\
\hline
\end{tabular}

${ }^{a}$ The differences of frequencies of PRNP mutations between Europeans and East Asians were measured by the Chi-square test or Fisher's exact test. gCJD, genetic Creutzfeldz-Jakob diseases; GSS, Gerstmann-Sträussler-Scheinker syndrome; FFI, fatal familial insomnia; n.s., not significant

FFIs caused by the mutation D178N in the PRNP gene associated with the M129 genotype have been reported worldwide. However, there are also clear geographical and race-associated variations. FFI is predominant in some regions of Europe, such as in Spain and Germany, where $56.8 \%(25 / 44)$ and $25 \%(17 / 68)$ of genetic prion diseases are FFI, respectively [34]. It is worth emphasizing that FFI cases are common in the Han Chinese population, which reaches to the first most common PRNP mutation in all identified mutations associated with genetic prion diseases in China [36], revealing a distinct profile compared with those in Japan and Korea (see Table 1). A study further addressing PRNP mutations among different ethnic groups is warranted.

The age at onset of genetic prion diseases is often earlier than that of SCJD, ranging from 30 to 55 years for gCJD, 40 to 60 years for GSS, and 20 to 72 years for FFI [43]. Although gCJD cases with point mutations have an earlier median age of death compared with that of sCJD cases, there is no difference between gCJD cases with point mutations and SCJD in the mean duration of the disease [44-46]. Meanwhile, gCJD cases with extra insertional octarepeat sequences, as well as GSS and FFI cases often have a relatively protracted duration of illness in Caucasians [34, 47, 48]. Relatively long clinical durations are also observed in Chinese FFI cases [49] and Japanese GSS patients [26].
In addition to these disease-related mutations, polymorphisms have also been described in $\operatorname{PrP}[32,50]$. In particular, single nucleotide polymorphisms (SNPs) at codons 129 and 219 of the PRNP gene represent susceptibility factors for human prion diseases [51, 52]. The pattern of SNP at codon 129 greatly varies between Caucasians and East Asians. An overwhelming percentage of East Asians (92\% to 94 \%) exhibit methionine/ methionine homozygote at codon 129 (M129M), but a much lower percentage of Caucasians have this polymorphism (32\% to $45 \%)$ [43]. Homozygosity at codon129 (M/V polymorphism) is a strong risk factor for the development of sCJD in Caucasians [15, 53-55]. Moreover, all vCJD cases with clinical symptoms and genetic analysis worldwide are M129M homozygous [56]. Homozygosity at a different PRNP polymorphism, E219K, seems to also be a risk factor for the development of sCJD in Korean and Japanese populations, but not in Caucasian populations $[16,52,57-59]$. In addition, PRNP codon 129 polymorphism has obvious effects on the clinical, neuropathological, and pathogenic features of prion disease. For instance, in the population with the $\mathrm{D} 178 \mathrm{~N}$ mutation in the PRNP gene, the codon 129 polymorphism determines the type of disease: people with the M129M mutation suffer from FFI and those with the M129V mutation acquire gCJD [60, 61]. 


\section{iCJD}

In 1974, iatrogenic CJD (iCJD) was firstly described in a person who received cadaveric corneal transplant from a patient with CJD [62]. Since then, several cases of human prion disease have been confirmed to be associated with iatrogenic transmission of CJD by the use of stereotactic intracerebral electroencephalogram needles or neurosurgical instruments [63-67]. Additionally, corneal grafts and the gonadotropin hormone $[68,69]$ can also cause iCJD. Because of the long incubation time of $\mathrm{iCJD}$, it is usually very difficult to attribute the disease to a special medical service in the lifespan of a patient. Therefore, the numbers of iCJD cases might be underestimated. Historically, large outbreaks of human iCJD cases have been reported via two different medical pathways: one is cadavericdura mater grafts [16], and the other is intramuscular injection of contaminated cadaveric pituitary-derived human growth hormone (hGH) and gonadotropin hormone [70]. Since the first identification of dura mater graft-associated iCJD in 1987, at least 228 cases have been reported worldwide. Nearly two thirds of cases come from Japan, with some European countries, such as France, Spain, Germany, Italy, and the Netherlands, also reporting iCJD. Cases have also been reported from Australia (five cases), South Africa (one case), Argentina (one case), the US (four cases), and South Korea (two cases) [68]. At least 226 hGH-related iCJD caseshave been reported worldwide, mostly in France (119 cases), the United Kingdom, UK (65 cases) and the US (29 cases), and a few cases in Brazil (two cases), New Zealand (six cases) and Qatar (one case) [68]. The global distribution of iCJD cases associated with dura mater grafts and the hGH is shown in Fig. 2. With the availability of recombinant hGH and the initiation of separated processing of individual dura mater grafts, the transmission pathways of these two kinds of iCJD have been successfully eradicated and almost no new cases have been reported in the past few years [70]. So far, there have been no reports of dura mater graft-associated or hGH-related iCJD in China.

The clinicopathological features of dura mater graftassociated iCJD cases resemble those of sCJD cases. However, in Japan, approximately one third of these cases have atypical features (slow progression, non-characteristic electroencephalogram tracings, plaque deposition, and an atypical prion protein molecular signature on Western blots), suggesting the possibility of two different types of infectious agents [71, 72]. The incubation periods are in the range of 1.3 to 30 years (mean: 12) worldwide [68]. The clinicopathological features of hGH-related iCJD cases resemble those of Kuru. The incubation periods vary from five to 42 years worldwide (mean:17) [68]. Those with the M129M mutation are at risk for acquiring hGH-related iCJD in France and in the US, but not in the UK $[68,73,74]$.
vCJD

The first 10 vCJD cases were reported in April 1996 in the UK [70, 75]. As of April 2015, 229 vCJD cases have been reported from seven European (UK, France, Spain, Republic of Ireland, Netherlands, Italy, and Portugal) and five nonEuropean countries or regions (US, Canada, Saudi Arabia, Japan, and China-Taiwan). Among them, 177 cases were reported from the UK [76]. In 2000, the annual number of deaths from vCJD in the UK reached a peak of 28. Since 2006, the annual deaths from vCJD have dramatically reduced, with 2-5 from 2006 to 2011, none in 2012, and only one in 2013 [77]. Since 2014, no more vCJD cases have been reported (see Fig. 3). Outside of the UK, France is the most affected country, with $27 \mathrm{vCJD}$ cases reported from 1996 to 2014, which is thought to be related to the peak in the volume of beef imports from the UK from 1985 to 1995 [78]. This potential relationship is shown by the peak of the number of deaths from vCJD in France in 2005, five years after a similar peak in the number of deaths occurred in the UK $[78,79]$. Additionally, three East Asian vCJD cases has been identified in Hong Kong SAR [80], Japan [81, 82], and China-Taiwan [83]. All three are assumed to be imported cases from the UK due to patients who either previously resided in or travelled to the UK bringing them in. The median age of onset is 27 years (range: 12-74) and the median duration of the disease is 14 months in the UK (range: 6-40). In France, despite a median age of onset is 35 years (range: 18-57), which is higher than in the UK, all other data are similar [84]. The disease duration in Asians (mean 28.3, range 14-43 months) seems to be longer than in patients in the UK and France [83]. A further study supports the hypothesis that a single strain of infectious agent is responsible for all vCJD infections [85]. Probable secondary transmission of vCJD via blood transfusions has been reported [86]. Animal experiments have shown that the M129V heterozygote is less sensitive to the transmission of vCJD and bovine spongiform encephalopathy (BSE) agents [87, 88]. Thus, vCJD with long incubation periods in individuals with M129V and V129Vgenotypes and secondary iatrogenic transmission of vCJD are still serious public health concerns [89-93].

\section{Surveillance of human prion diseases}

Due to the impact that the BSE outbreak and the emergence of vCJD has had on public health, many countries and regions have initiated or re-initiated their surveillance programs for human prion diseases. Initially, two major surveillance networks for human prion diseases were created by the European Commission. One is the EuroCJD established in 1993 by seven countries (Austria, France, Germany, Italy, Netherlands, Slovakia, and the UK), which was later expanded to other European and non-European countries such as Australia, Canada, and Spain. The other 


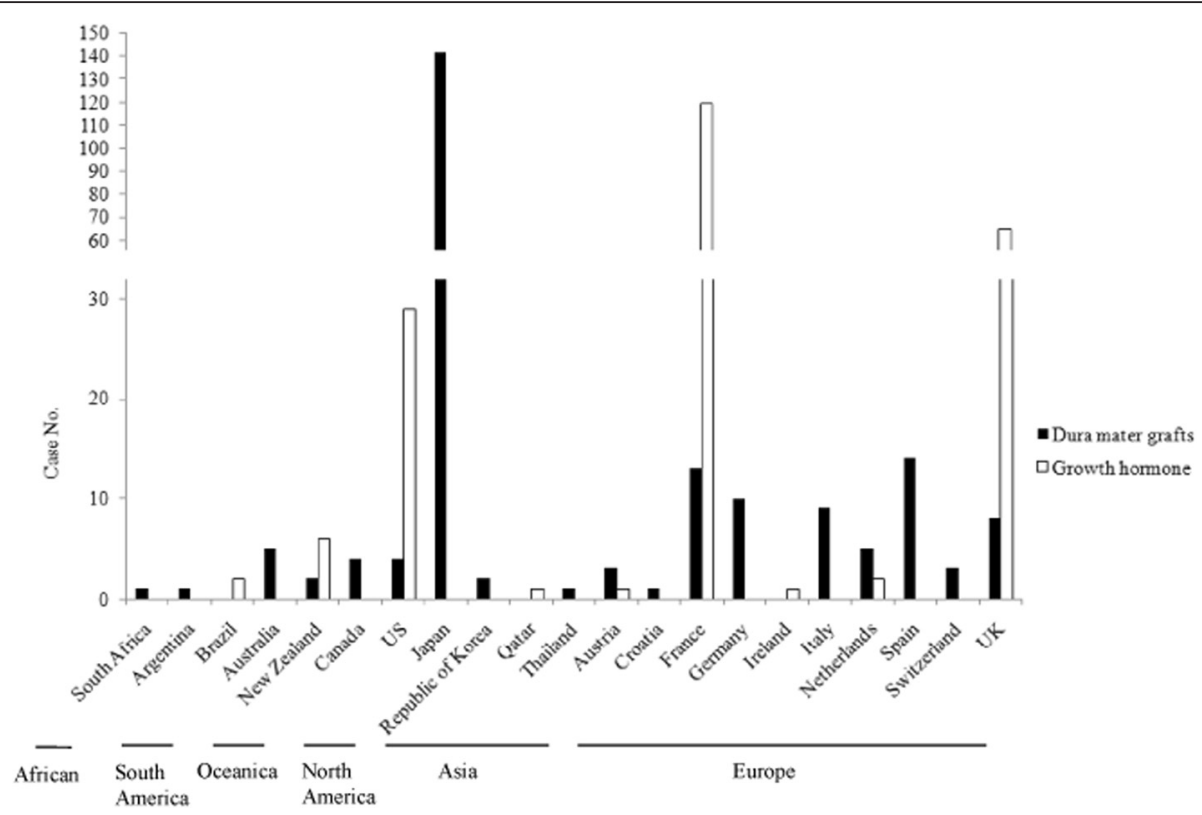

Fig. 2 The distribution ofdura mater graft-associated and hGH-related iCJD casesglobally

one is NeuroCJD initiated in 1998, which includes all the other European countries and Israel [18, 34, 79]. In 2008, the CJD International Surveillance Network (formerly EuroCJD) was launched and funded by the European Center for Disease Prevention and Control (CDC) $[94,95]$. The network includes 28 collaborating centers from European Union (EU) Member States, European Free Trade Association countries, and eight non-EU countries/ regions (Argentina, Australia, Japan, Canada, Mexico, China, Israel, USA, and China-Taiwan) (see Fig. 4). The primary objective of the network is to identify all cases of vCJD in the $\mathrm{EU}$ and provide accurate data on the worldwide incidence of vCJD through collaborations with other non-EU countries.

Besides these major CJD surveillance networks, there are several other CJD surveillance and/or research groups intra- and internationally, including CJD surveillance in
Central and Eastern European countries [96]. NeuroPrion, which aims to structure and integrate the efforts of the main European prion research teams for the effective management of prion diseases is funded by the European Commission and has been operating since 2003 [18]. In 1997, the National Prion Disease Pathology Surveillance Center of the US was established at the Case Western Reserve University [97] and the following year, the Canadian CJD surveillance system was initiated by the Public Health Agency of Canada [98]. In 1999, the CJD Surveillance Committee was established at the Kanazawa University of Japan, which started carrying out surveillance of CJD nationwide [16]. The CJD surveillance program in the Republic of Korea was established in 2001 and it is supported by the Korean CDCs [18]. In 2006, the China CJD surveillance program was initiated, which is supported by the Chinese CDC [22].

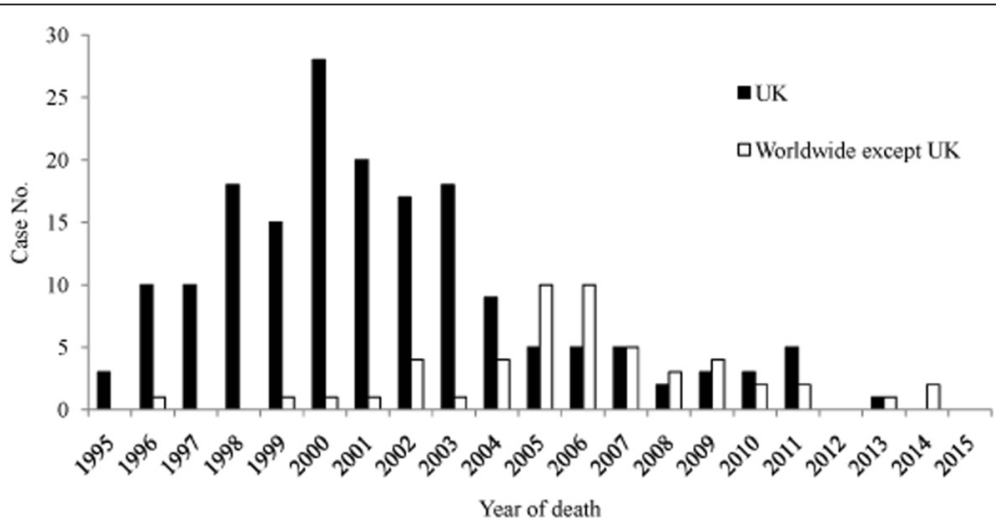

Fig. 3 Number of deaths from VCJD in the UK and outside of the UK from 1995 to 2015 


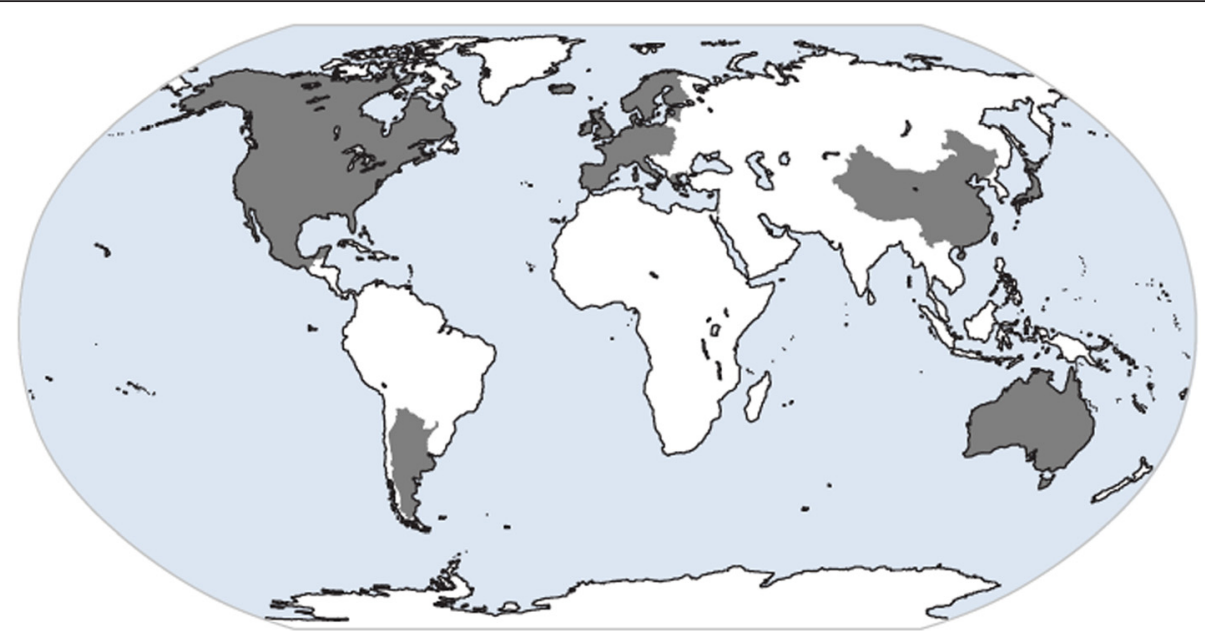

Fig. 4 Countries (marked in gray) where active CJD surveillance is officially conducted under the framework of the CJD International Surveillance Network

CJD surveillance systems have some unique features compared with other public health surveillance systems. One is that due to a lack of approved biomarkers for CJDs, specific types of clinical and laboratory approaches are critical to effectively diagnose and monitor CJDs. The other is that CJD surveillance systems are primarily dependent on reports from physicians, especially neurologists and neuropathologists in regional hospitals and medical centers where first visit for most patients. Thus, the experiences of these specialists directly determine the quality of the collected specimens, such as accurate identify the clinical manifestations of CJD or supply the appropriate specimens to CJD surveillance center. Both aspects seriously impact the sensitivity of CJD surveillance.

\section{Conclusion}

Human prion diseases are invariably fatal neurodegenerative disorders. The emergence of the novel prion strain, which include the causative agent of vCJD, has created an important public health concern. New prion strains continually emerge in livestock, and their threats to other domestic animals and humans are uncertain and need long-term evaluation and assessment. Strategies for early diagnosis of and therapies to treat human prion diseases remain unavailable. Therefore, except for developing treatment for prion diseases, the most feasible method to prevent these diseases from spreading, either via human-to-human or zoonotic transmission, is active surveillance and improving the sensitivity and specificity of laboratory diagnostic procedures. This will require more clinicians and experts participating in regional, national, and global systems by investing more of an effort toward reliable and accurate diagnostic methods for the control of prion diseases.

\section{Additional file}

Additional file 1: Multilingual abstracts in the six official working languages of the United Nations. (PDF $201 \mathrm{~kb}$ )

\section{Abbreviations}

BSE: bovine spongiform encephalopathy; CDC: center for disease control and prevention; CJD: Creutzfeldt-Jakob disease; EU: European union;

EuroCJD: European Creutzfeldt-Jakob disease surveillance network; fCJD: familial Creutzfeldt-Jakob disease; FFl: fatal familial insomnia; gCJD: genetic CreutzfeldtJakob disease; GSS: gerstmann-sträussler-scheinker syndrome; hGH: human growthhormone; iCJD: iatrogenic Creutzfeldt-Jakob disease; M129M: methionine/ methionine homozygote at codon 129; PRNP: human gene encoding for the major prion protein; $\mathrm{PrP}$ : prion protein; $\mathrm{PrPC}^{\mathrm{C}}$ : cellular prion protein; $\mathrm{PrP}^{\mathrm{SC}}$ : scrapielike prion protein; SCJD: sporadic Creutzfeldt-Jakob disease; SNP: single nucleotide polymorphism; TSEs: transmissible spongiform encephalopathies; UK: United Kingdom; US: United States; VCJD: variant Creutzfeldt-Jakob disease.

\section{Competing interests}

The authors declare that they have no competing interests.

\section{Authors' contributions}

CC designed the study, analyzed the data, and prepared the paper. XPD, who is the corresponding author, designed the study and prepared the paper. Both authors read and approved the final paper.

\section{Authors' information}

Cao Chen: State Key Laboratory for Infectious Disease Prevention and Control, National Institute for Viral Disease Control and Prevention, Chinese Center for Disease Control and Prevention, Changbai Rd 155, Beijing 102206, China; Collaborative Innovation Center for Diagnosisand Treatment of InfectiousDiseases, Zhejiang University, Hangzhou 310003, China.

Xiao-Ping Dong: State Key Laboratory for Infectious Disease Prevention and Control, National Institute for Viral Disease Control and Prevention, Chinese Center for Disease Control and Prevention, Changbai Rd 155, Beijing 102206, China; Collaborative Innovation Center for Diagnosisand Treatment of InfectiousDiseases, Zhejiang University, Hangzhou 310003, China; Chinese Academy of Sciences Key Laboratory of Pathogenic Microbiology and Immunology, Institute of Microbiology, Chinese Academy of Sciences, Beijing 100101, China.

\section{Funding}

This work was supported by the Chinese National Natural Science Foundation Grants (81401670), the China Mega-Project for Infectious Diseases (2011ZX10004101, 2012ZX10004215), and the SKLID Development Grant (2012SKLID102). 


\section{Author details}

'State Key Laboratory for Infectious Disease Prevention and Control, National Institute for Viral Disease Control and Prevention, Chinese Center for Disease Control and Prevention, Changbai Rd 155, Beijing 102206, China.

${ }^{2}$ Collaborative Innovation Center for Diagnosis and Treatment of Infectious Diseases, Zhejiang University, Hangzhou 310003, China. ${ }^{3}$ Chinese Academy of Sciences Key Laboratory of Pathogenic Microbiology and Immunology, Institute of Microbiology, Chinese Academy of Sciences, Beijing 100101, China.

\section{Received: 22 January 2016 Accepted: 4 May 2016} Published online: 02 June 2016

\section{References}

1. Prusiner SB. The prion diseases. Brain Pathol. 1998:8(3):499-513.

2. Knight R, Brazier M, Collins SJ. Human prion diseases: cause, clinical and diagnostic aspects. Contrib Microbiol. 2004;11:72-97.

3. Prusiner SB. Prions. Proc Natl Acad Sci U S A. 1998;95(23):13363-83.

4. Mead S, Stumpf MP, Whitfield J, Beck JA, Poulter M, Campbell T, et al. Balancing selection at the prion protein gene consistent with prehistoric kurulike epidemics. Science. 2003;300(5619):640-3. doi:10.1126/science. 1083320.

5. Collinge J. Prion diseases of humans and animals: their causes and molecular basis. Annu Rev Neurosci. 2001:24:519-50. doi:10.1146/annurev.neuro.24.1.519.

6. Ryou C. Prions and prion diseases: fundamentals and mechanistic details. J Microbiol Biotechnol. 2007;17(7):1059-70.

7. Parchi P, Castellani R, Capellari S, Ghetti B, Young K, Chen SG, et al. Molecular basis of phenotypic variability in sporadic Creutzfeldt-Jakob disease. Ann Neurol. 1996;39(6):767-78. doi:10.1002/ana.410390613.

8. Shibuya S, Higuchi J, Shin RW, Tateishi J, Kitamoto T. Protective prion protein polymorphisms against sporadic Creutzfeldt-Jakob disease. Lancet. 1998;351(9100):419. doi:10.1016/S0140-6736(05)78358-6.

9. Parchi P, Giese A, Capellari S, Brown P, Schulz-Schaeffer W, Windl O, et al. Classification of sporadic Creutzfeldt-Jakob disease based on molecular and phenotypic analysis of 300 subjects. Ann Neurol. 1999:46(2):224-33.

10. Head MW, Bunn TJ, Bishop MT, McLoughlin V, Lowrie S, McKimmie CS, et al. Prion protein heterogeneity in sporadic but not variant Creutzfeldt-Jakob disease: UK cases 1991-2002. Ann Neurol. 2004;55(6):851-9. doi:10.1002/ana. 20127.

11. Parchi P, Notari S, Weber P, Schimmel H, Budka H, Ferrer I, et al. Interlaboratory assessment of PrPSc typing in creutzfeldt-jakob disease: a Western blot study within the NeuroPrion Consortium. Brain Pathol. 2009; 19(3):384-91. doi:10.1111/j.1750-3639.2008.00187.x

12. Parchi P, Strammiello R, Notari S, Giese A, Langeveld JP, Ladogana A, et al. Incidence and spectrum of sporadic Creutzfeldt-Jakob disease variants with mixed phenotype and co-occurrence of PrPSc types: an updated classification. Acta Neuropathol. 2009;118(5):659-71. doi:10.1007/s00401-009-0585-1.

13. Knight RS, Will RG. Prion diseases. J Neurol Neurosurg Psychiatry. 2004;75 Suppl 1:i36-42.

14. Heinemann U, Krasnianski A, Meissner B, Varges D, Kallenberg K, SchulzSchaeffer WJ, et al. Creutzfeldt-Jakob disease in Germany: a prospective 12year surveillance. Brain. 2007;130(5):1350-9.

15. Brandel JP, Salomon D, Capek I, Vaillant V, Alperovitch A. Epidemiological surveillance of Creutzfeldt-Jakob in France. Rev Neurol (Paris). 2009;165(8-9): 684-93.

16. Nozaki I, Hamaguchi T, Sanjo N, Noguchi-Shinohara M, Sakai K, Nakamura Y, et al. Prospective 10-year surveillance of human prion diseases in Japan. Brain. 2010;133(10):3043-57.

17. Begue C, Martinetto H, Schultz M, Rojas E, Romero C, D'Giano C, et al. Creutzfeldt-Jakob disease surveillance in Argentina, 1997-2008. Neuroepidemiology. 2011;37(3-4):193-202.

18. Lee J, Hyeon JW, Kim SY, Hwang KJ, Ju YR, Ryou C. Review: Laboratory diagnosis and surveillance of Creutzfeldt-Jakob disease. J Med Virol. 2015; 87(1):175-86. doi:10.1002/jmv.24004.

19. Creutzfeldt HG. Uber eine eigenartige herdformige Erkrankung des Zentralnervensystems. Z Neurol U Psychiatr. 1920;57:1-18.

20. Jakob A. Uber eine eigenartige Erkrankung des Zentral-nervensystems mit bemerkenswertem anatomischem Befunde (spastische pseudosklerotische Encephalomyelopathie mit disseminierten Degenerationsherden). Dtsch Z Nervenheilk. 1921;70:132-46.
21. WHO. WHO manual for surveillance of human transmissible spongiform encephalopathies including variant Creutzfeldt-Jakob disease. WHO Communicable Disease Surveillance and Response. 2003.

22. Gao C, Shi Q, Tian C, Chen C, Han J, Zhou W, et al. The epidemiological, clinical, and laboratory features of sporadic Creutzfeldt-Jakob disease patients in China: surveillance data from 2006 to 2010. PLoS One. 2011;6(8):e24231.

23. Imran M, Mahmood S. An overview of human prion diseases. Virol J. 2011;8: 559. doi:10.1186/1743-422x-8-559.

24. Chen C, Wang JC, Shi Q, Zhou W, Zhang XM, Zhang J, et al. Analyses of the survival time and the influencing factors of chinese patients with prion diseases based on the surveillance data from 2008-2011. PLoS One. 2013; 8(5):e62553.

25. Collins SJ, Sanchez-Juan P, Masters CL, Klug GM, Van Duijn C, Poleggi A, et al. Determinants of diagnostic investigation sensitivities across the clinical spectrum of sporadic Creutzfeldt-Jakob disease. Brain. 2006;129(Pt 9):2278-87.

26. Nagoshi K, Sadakane A, Nakamura Y, Yamada M, Mizusawa H. Duration of prion disease is longer in Japan than in other countries. J Epidemiol. 2011; 21(4):255-62.

27. Ladogana A, Puopolo M, Croes EA, Budka H, Jarius C, Collins S, et al. Mortality from Creutzfeldt-Jakob disease and related disorders in Europe, Australia, and Canada. Neurology. 2005;64(9):1586-91. doi:10.1212/01.WNL. 0000160117.56690.B2

28. Doi Y, Yokoyama T, Sakai M, Nakamura Y. Creutzfeldt-Jakob disease mortality in Japan, 1979-2004: analysis of national death certificate data. J Epidemiol. 2007; 17(4):133-9.

29. Shi Q, Zhang XC, Zhou W, Xiao K, Chen C, Zhang HY, et al. Analysis of the advantage features of Beijing surveillance network for Creutzfeldt-Jakob disease. Prion. 2015:9(4):304-14. doi:10.1080/19336896.2015.1075115.

30. Holman RC, Belay ED, Christensen KY, Maddox RA, Minino AM, Folkema AM, et al. Human prion diseases in the United States. PLoS One. 2010:5(1) e8521. doi:10.1371/journal.pone.0008521.

31. Maddox RA, Holman RC, Belay ED, Cheek JE, Yorita KL, Schonberger LB. Creutzfeldt-Jakob disease among American Indians and Alaska Natives in the United States. Neurology. 2006:66(3):439-41. doi:10.1212/01.wnl.000019 6473.46805.61.

32. Mastrianni JA. The genetics of prion diseases. Genet Med. 2010;12(4):187-95. doi:10.1097/GIM.0b013e3181cd7374.

33. Group E. Genetic epidemiology of Creutzfeldt-Jakob disease in Europe. Rev Neurol (Paris). 2001;157(6-7):633-7.

34. Kovacs GG, Puopolo M, Ladogana A, Pocchiari M, Budka H, Van Duijn C, et al. Genetic prion disease: the EUROCJD experience. Hum Genet. 2005;118(2): 166-74. doi:10.1007/s00439-005-0020-1.

35. Ladogana A, Puopolo M, Poleggi A, Almonti S, Mellina V, Equestre M, et al. High incidence of genetic human transmissible spongiform encephalopathies in Italy. Neurology. 2005;64(9):1592-7. doi:10.1212/01.WNL. 0000160118.26865 .11

36. Shi Q, Zhou W, Chen C, Zhang BY, Xiao K, Zhang XC, et al. The Features of Genetic Prion Diseases Based on Chinese Surveillance Program. PLoS One. 2015:10(10):e0139552. doi:10.1371/journal.pone.0139552.

37. Jeong BH, Ju WK, Huh K, Lee EA, Choi IS, Im JH, et al. Molecular analysis of prion protein gene (PRNP) in Korean patients with Creutzfeldt-Jakob disease. J Korean Med Sci. 1998;13(3):234-40.

38. Choi BY, Kim SY, Seo SY, An SS, Kim S, Park SE, et al. Mutations at codons 178, 200-129, and 232 contributed to the inherited prion diseases in Korean patients. BMC Infect Dis. 2009:9:132. doi:10.1186/1471-2334-9-132.

39. Jeong BH, Jeon YC, Lee YJ, Cho HJ, Park SJ, Chung DI, et al. CreutzfeldtJakob disease with the V203I mutation and M129V polymorphism of the prion protein gene (PRNP) and a $17 \mathrm{kDa}$ prion protein fragment. Neuropathol Appl Neurobiol. 2010;36(6):558-63. doi:10.1111/j.1365-2990. 2010.01094.x.

40. Yang TI, Jung DS, Ahn BY, Jeong BH, Cho HJ, Kim YS, et al. Familial CreutzfeldtJakob disease with V180I mutation. J Korean Med Sci. 2010;25(7):1097-100. doi:10.3346/jkms.2010.25.7.1097.

41. Moe Lee S, Ran Ju Y, Choi BY, Wook Hyeon J, Sun Park J, Kyeong Kim C, et al. Genotype patterns and characteristics of PRNP in the Korean population. Prion. 2012:6(4):375-82. doi:10.4161/pri.20195.

42. Yeo MJ, Lee SH, Lee SY, Jeon YC, Park SJ, Cho HJ, et al. Familial CreutzfeldtJakob disease with a mutation at codon 180 presenting with an atypical phenotype. J Clin Neurosci. 2013;20(1):180-2. doi:10.1016/j.jocn.2012.01.044.

43. Jeong $\mathrm{BH}$, Kim YS. Genetic studies in human prion diseases. J Korean Med Sci. 2014;29(5):623-32. doi:10.3346/jkms.2014.29.5.623. 
44. Alperovitch A, Zerr I, Pocchiari M, Mitrova E, De Pedro CJ, Hegyi I, et al. Codon 129 prion protein genotype and sporadic Creutzfeldt-Jakob disease. Lancet. 1999;353(9165):1673-4.

45. Zerr I, Pocchiari M, Collins S, Brandel JP, De Pedro CJ, Knight RS, et al Analysis of EEG and CSF 14-3-3 proteins as aids to the diagnosis of Creutzfeldt-Jakob disease. Neurology. 2000;55(6):811-5.

46. Pocchiari M, Puopolo M, Croes EA, Budka H, Gelpi E, Collins S, et al. Predictors of survival in sporadic Creutzfeldt-Jakob disease and other human transmissible spongiform encephalopathies. Brain. 2004;127(Pt 10):2348-59. doi:10.1093/brain/awh249.

47. Vital C, Gray F, Vital A, Ferrer X, Julien J. Prion disease with octapeptide repeat insertion. Clin Exp Pathol. 1999;47(3-4):153-9.

48. Kovacs GG, Trabattoni G, Hainfellner JA, Ironside JW, Knight RS, Budka H. Mutations of the prion protein gene phenotypic spectrum. J Neurol. 2002; 249(11):1567-82. doi:10.1007/s00415-002-0896-9.

49. Shi Q, Chen C, Gao C, Tian C, Zhou W, Zhang B, et al. Clinical and familial characteristics of ten chinese patients with fatal family insomnia. Biomed Environ Sci. 2012;25(4):471-5.

50. Brown K, Mastrianni JA. The prion diseases. J Geriatr Psychiatry Neurol. 2010 23(4):277-98. doi:10.1177/0891988710383576.

51. Lloyd S, Mead S, Collinge J. Genetics of prion disease. Top Curr Chem. 2011; 305:1-22. doi:10.1007/128_2011_157.

52. Shibuya S, Higuchi J, Shin RW, Tateishi J, Kitamoto T. Codon 219 Lys allele of PRNP is not found in sporadic Creutzfeldt-Jakob disease. Ann Neurol. 1998:43(6):826-8. doi:10.1002/ana.410430618.

53. Jansen C, Parchi P, Capellari S, Ibrahim-Verbaas CA, Schuur M, Strammiello R, et al. Human prion diseases in the Netherlands (1998-2009): clinical, genetic and molecular aspects. PLoS One. 2012;7(4), e36333. doi:10.1371/journal. pone.0036333

54. Laplanche JL, Delasnerie-Laupretre N, Brandel JP, Chatelain J, Beaudry P, Alperovitch A, et al. Molecular genetics of prion diseases in France. French Research Group on Epidemiology of Human Spongiform Encephalopathies. Neurology. 1994;44(12):2347-51.

55. Palmer MS, Dryden AJ, Hughes JT, Collinge J. Homozygous prion protein genotype predisposes to sporadic Creutzfeldt-Jakob disease. Nature. 1991; 352(6333):340-2. doi:10.1038/352340a0.

56. Ward HJ, Head MW, Will RG, Ironside JW. Variant Creutzfeldt-Jakob disease. Clin Lab Med. 2003;23(1):87-108.

57. Jeong $\mathrm{BH}$, Lee $\mathrm{KH}$, Kim NH, Jin JK, Kim Jl, Carp Rl, et al. Association of sporadic Creutzfeldt-Jakob disease with homozygous genotypes at PRNP codons 129 and 219 in the Korean population. Neurogenetics. 2005;6(4): 229-32. doi:10.1007/s10048-005-0016-y.

58. Jeong BH, Nam JH, Lee YJ, Lee KH, Jang MK, Carp Rl, et al. Polymorphisms of the prion protein gene (PRNP) in a Korean population. J Hum Genet. 2004:49(6):319-24. doi:10.1007/s10038-004-0150-7.

59. Petraroli R, Pocchiari M. Codon 219 polymorphism of PRNP in healthy Caucasians and Creutzfeldt-Jakob disease patients. Am J Hum Genet. 1996; 58(4):888-9

60. Capellari S, Strammiello R, Saverioni D, Kretzschmar H, Parchi P. Genetic Creutzfeldt-Jakob disease and fatal familial insomnia: insights into phenotypic variability and disease pathogenesis. Acta Neuropathol. 2011; 121(1):21-37. doi:10.1007/s00401-010-0760-4.

61. Gambetti P, Kong Q, Zou W, Parchi P, Chen SG. Sporadic and familial CJD: classification and characterisation. Br Med Bull. 2003;66:213-39.

62. Duffy P, Wolf J, Collins G, DeVoe AG, Streeten B, Cowen D. Letter: Possible person-to-person transmission of Creutzfeldt-Jakob disease. N Engl J Med. 1974;290(12):692-3.

63. Bernoulli C, Siegfried J, Baumgartner G, Regli F, Rabinowicz T, Gajdusek DC, et al. Danger of accidental person-to-person transmission of CreutzfeldtJakob disease by surgery. Lancet. 1977;1(8009):478-9.

64. Will RG, Matthews WB. Evidence for case-to-case transmission of CreutzfeldtJakob disease. J Neurol Neurosurg Psychiatry. 1982;45(3):235-8.

65. Taylor DM, Bell JE. Prevention of iatrogenic transmission of CreutzfeldtJakob disease. Lancet. 1993;341(8859):1543-4.

66. El Hachimi KH, Chaunu MP, Cervenakova L, Brown P, Foncin JF. Putative neurosurgical transmission of Creutzfeldt-Jakob disease with analysis of donor and recipient: agent strains. C R Acad Sci III. 1997;320(4):319-28.

67. Hamaguchi T, Noguchi-Shinohara M, Nozaki I, Nakamura Y, Sato T, Kitamoto T, et al. The risk of iatrogenic Creutzfeldt-Jakob disease through medical and surgical procedures. Neuropathology. 2009:29(5):625-31. doi:10.1111/j.14401789.2009.01023.x
68. Brown P, Brandel JP, Sato T, Nakamura Y, Mackenzie J, Will RG, et al. latrogenic Creutzfeldt-Jakob disease, final assessment. Emerg Infect Dis. 2012;18(6):901-7. doi:10.3201/eid1806.120116.

69. Appleby BS, Lu M, Bizzi A, Phillips MD, Berri SM, Harbison MD, et al. latrogenic Creutzfeldt-Jakob disease from commercial cadaveric human growth hormone. Emerg Infect Dis. 2013;19(4):682-4. doi:10.3201/eid1904.121504.

70. Will RG. Acquired prion disease: iatrogenic CJD, variant CJD, kuru. Br Med Bull. 2003;66:255-65.

71. Noguchi-Shinohara M, Hamaguchi T, Kitamoto T, Sato T, Nakamura Y, Mizusawa $\mathrm{H}$, et al. Clinical features and diagnosis of dura mater graft associated Creutzfeldt Jakob disease. Neurology. 2007;69(4):360-7. doi:10. 1212/01.wnl.0000266624.63387.4a.

72. Yamada M, Noguchi-Shinohara M, Hamaguchi T, Nozaki I, Kitamoto T, Sato T, et al. Dura mater graft-associated Creutzfeldt-Jakob disease in Japan: clinicopathological and molecular characterization of the two distinct subtypes. Neuropathology. 2009;29(5):609-18. doi:10.1111/j.1440-1789.2008.00987.x.

73. Brandel JP, Preece M, Brown P, Croes E, Laplanche JL, Agid Y, et al. Distribution of codon 129 genotype in human growth hormone-treated CJD patients in France and the UK. Lancet. 2003:362(9378):128-30. doi:10. 1016/S0140-6736(03)13867-6.

74. Rudge P, Jaunmuktane Z, Adlard P, Bjurstrom N, Caine D, Lowe J, et al. latrogenic CJD due to pituitary-derived growth hormone with genetically determined incubation times of up to 40 years. Brain. 2015;138(Pt 11):3386-99. doi:10.1093/brain/awv235

75. Will RG, Ironside JW, Zeidler M, Cousens SN, Estibeiro K, Alperovitch A, et al. A new variant of Creutzfeldt-Jakob disease in the UK. Lancet. 1996; 347(9006):921-5.

76. Statistics NCRSUDaRLNCM. National CJD Research \& Surveillance Unit Data and Reports Latest NCJDSRU CJD Monthly Statistics. [update in April 2015]. Available from: http://www.cjd.ed.ac.uk/documents/figs.pdf.

77. Diack AB, Head MW, McCutcheon S, Boyle A, Knight R, Ironside JW, et al. Variant CJD. 18 years of research and surveillance. Prion. 2014;8(4):286-95. doi:10.4161/pri.29237.

78. Chadeau-Hyam M, Alperovitch A. Risk of variant Creutzfeldt-Jakob disease in France. Int J Epidemiol. 2005;34(1):46-52. doi:10.1093/ije/dyh374.

79. Brandel JP, Peckeu L, Haik S. The French surveillance network of CreutzfeldtJakob disease. Epidemiological data in France and worldwide. Transfus Clin Biol. 2013:20(4):395-7. doi:10.1016/j.tracli.2013.02.029.

80. Kay R, Lau WY, Ng HK, Chan YL, Lyon DJ, Van Hasselt CA. Variant CreutzfeldtJakob disease in Hong Kong. Hong Kong medical journal = Xianggang yi xue za zhi/Hong Kong Academy of Medicine. 2001;7(3):296-8.

81. Yamada M, Variant Cjd Working Group C-JDSCJ. The first Japanese case of variant Creutzfeldt-Jakob disease showing periodic electroencephalogram. Lancet. 2006;367(9513):874. doi:10.1016/S0140-6736(06)68344-X.

82. Shinde A, Kunieda T, Kinoshita Y, Wate R, Nakano S, Ito H, et al. The first Japanese patient with variant Creutzfeldt-Jakob disease (vCJD). Neuropathology. 2009;29(6):713-9. doi:10.1111/j.1440-1789.2009.01006.x.

83. Yang CW, Fuh JL, Wang SJ, Lirng JF, Yang CC, Cheng SJ. Probable variant Creutzfeldt-Jakob disease in Asia: a case report from Taiwan and review of two prior cases. Psychiatry Clin Neurosci. 2010;64(6):652-8.

84. Brandel JP, Heath CA, Head MW, Levavasseur E, Knight R, Laplanche JL, et al. Variant Creutzfeldt-Jakob disease in France and the United Kingdom: Evidence for the same agent strain. Ann Neurol. 2009;65(3):249-56. doi:10.1002/ana.21583.

85. Diack AB, Ritchie D, Bishop M, Pinion V, Brandel JP, Haik S, et al. Constant transmission properties of variant Creutzfeldt-Jakob disease in 5 countries. Emerg Infect Dis. 2012;18(10):1574-9. doi:10.3201/eid1810.120792.

86. Wroe SJ, Pal S, Siddique D, Hyare H, Macfarlane R, Joiner S, et al. Clinical presentation and pre-mortem diagnosis of variant Creutzfeldt-Jakob disease associated with blood transfusion: a case report. Lancet. 2006;368(9552): 2061-7. doi:10.1016/S0140-6736(06)69835-8.

87. Asante EA, Linehan JM, Gowland I, Joiner S, Fox K, Cooper S, et al. Dissociation of pathological and molecular phenotype of variant Creutzfeldt-Jakob disease in transgenic human prion protein 129 heterozygous mice. Proc Natl Acad Sci U S A. 2006:103(28):10759-64. doi:10.1073/pnas.0604292103.

88. Wadsworth JD, Asante EA, Desbruslais M, Linehan JM, Joiner S, Gowland I, et al. Human prion protein with valine 129 prevents expression of variant CJD phenotype. Science. 2004;306(5702):1793-6. doi:10.1126/science.1103932.

89. Ironside JW, Bishop MT, Connolly K, Hegazy D, Lowrie S, Le Grice M, et al. Variant Creutzfeldt-Jakob disease: prion protein genotype analysis of positive appendix tissue samples from a retrospective prevalence study. BMJ. 2006;332(7551):1186-8. doi:10.1136/bmj.38804.511644.55. 
90. Wilson K, Ricketts MN. A new human genotype prone to variant CreutzfeldtJakob disease. BMJ. 2006;332(7551):1164-5. doi:10.1136/bmj.332.7551.1164.

91. Bishop MT, Pennington C, Heath CA, Will RG, Knight RS. PRNP variation in UK sporadic and variant Creutzfeldt Jakob disease highlights genetic risk factors and a novel non-synonymous polymorphism. BMC Med Genet. 2009; 10:146. doi:10.1186/1471-2350-10-146.

92. Kaski D, Mead S, Hyare H, Cooper S, Jampana R, Overell J, et al. Variant CJD in an individual heterozygous for PRNP codon 129. Lancet. 2009;374(9707): 2128. doi:10.1016/S0140-6736(09)61568-3.

93. Gill ON, Spencer Y, Richard-Loendt A, Kelly C, Dabaghian R, Boyes L, et al. Prevalent abnormal prion protein in human appendixes after bovine spongiform encephalopathy epizootic: large scale survey. BMJ. 2013;347: f5675. doi:10.1136/bmj.f5675.

94. Network C-JDIS. Creutzfeldt-Jakob Disease International Surveillance Network [Accessed in January 2016] Available from: http://www.eurocjd.ed.ac.uk/index. html.

95. Alcalde-Cabero E, Almazan-Isla J, Brandel JP, Breithaupt M, Catarino J, Collins $\mathrm{S}$, et al. Health professions and risk of sporadic Creutzfeldt-Jakob disease, 1965 to 2010. Euro Surveill. 2012;17:15.

96. Ladogana A, Sanchez-Juan P, Mitrova E, Green A, Cuadrado-Corrales N, Sanchez-Valle R, et al. Cerebrospinal fluid biomarkers in human genetic transmissible spongiform encephalopathies. J Neurol. 2009;256(10):1620-8. doi:10.1007/s00415-009-5163-x

97. (NPDPSC) NPDPSC. National Prion Disease Pathology Surveillance Center (NPDPSC). [Accessed in January 2016]. Available from: http://case.edu/med/ pathology/centers/npdpsc//index.html.

98. Coulthart MB, Jansen GH, Olsen E, Godal DL, Connolly T, Choi BC, et al. Diagnostic accuracy of cerebrospinal fluid protein markers for sporadic Creutzfeldt-Jakob disease in Canada: a 6-year prospective study. BMC Neurol. 2011;11:133. doi:10.1186/1471-2377-11-133.

\section{Submit your next manuscript to BioMed Central and we will help you at every step:}

- We accept pre-submission inquiries

- Our selector tool helps you to find the most relevant journal

- We provide round the clock customer support

- Convenient online submission

- Thorough peer review

- Inclusion in PubMed and all major indexing services

- Maximum visibility for your research

Submit your manuscript at www.biomedcentral.com/submit

C Biomed Central 